\title{
The Significance of Field Grow th and the Role of Enhanced Oil Recovery
}

\section{Introduction}

The importance of field growth cannot be overemphasized, especially in the context of a mature petroleum province or a country, such as the U.S., with declining domestic production and increasing imports. This fact sheet has been prepared to discuss some of the important aspects of field growth, particularly the role of enhanced oil recovery (EOR) processes.

Field growth is the increase in total proved reserves of an existing field through time as a result of such factors as (1) application of enhanced oil recovery (EOR) processes and horizontal well technology, (2) discovery of new pools (or reservoirs) or extensions of known pools (or reservoirs) in the existing fields, (3) improvement in reservoir characterization, and (4) development of more sophisticated and efficient reservoir simulators and data processing capabilities. The term reserves, in field (or reserve) growth, refers to the total proved reserves or the estimated ultimate recovery (EUR), which is equal to the sum of remaining proved reserves and cumulative production at the time of reporting.

In industry, reservoirs are periodically assessed for the remaining hydrocarbon reserves to optimize reservoir development strategies for better economic returns. These periodic assessments generally result in increased total proved reserves.

Potential additions to hydrocarbon (oil and gas) reserves come from two sources, new discoveries and existing fields. During the early phases of development in a petroleum province, new discoveries are the dominant source of reserve additions. Growth from existing fields (field growth) is somewhat obscure or insignificant in the early phases but becomes dominant in the final development phase. Attanasi and Root (1994) report that the growth of existing fields contributed about 90 percent of the additional U.S. reserves from 1978 through 1991. Field growth is crucial to the supply of petroleum to the U.S. and elsewhere in the world.

\section{Background}

Although the importance of field growth was first recognized by Arrington (1960), Attanasi and Root (1994) were the first to attempt to forecast the growth of oil and gas fields for the conterminous United States. Attanasi and Root (1994) used the proprietary Oil and Gas Integrated Field File (OGIFF) developed by the Energy Information Administration (EIA) of the U.S. Department of Energy (DOE), which estimates total reserves of crude oil and gas, to develop their model. A summary of the OGIFF was published in 1990 by the EIA (Energy and Information Administration, 1990). The 1993 version of the OGIFF database includes estimated total reserves (same as EUR) from 1977 through 1991 for all discovered U.S. oil and gas fields. In a subsequent paper, Attanasi and others (1999) reported that in the period 1992 through 1996, oil reserve additions from field growth were 33 percent lower and gas reserve additions from field growth were 25 percent higher than predicted by their earlier model. These differences are attributed primarily to the lower oil prices and higher gas prices during this period (Attanasi and others, 1999). Schmoker and Attanasi (1996) discuss the importance of reserve (or field) growth to the U.S. natural gas supply.

\section{Importance of Field Grow th Studies}

During 1998, U.S. petroleum production and imports were 8.0 and 10.38 million barrels per day, respectively (Energy Information Administration, 1998). Figure 1 shows the historical petroleum production (including crude oil, lease condensate and natural gas plant liquids) and petroleum imports (including crude oil and petroleum products) from 1949 through 1998.

The decline of domestic production and increase of petroleum imports reminds us of our increasing dependence on foreign petroleum supplies. Combined with the fact that the probability of finding new discoveries is continually decreasing reinforces the need for domestic field growth, which in turn results mainly from successful application of proven technologies in all phases of oil and gas exploration and development. Moreover, the economics of EOR projects is significantly improved when the use of existing wells, including stripper wells (producing 10-15 barrels per day or less) and associated facilities, is maximized. Once wells and production facilities become inactive for a long term, putting them back into operation for either production or application of enhanced oil recovery (EOR) methods may not be economically viable, and opportunities for reserve growth are diminished.

Technologic advancements in various phases of the oil industry have contributed to an increase field growth. Some of the advancements include the use of 4-D seismic technique; improved drilling practices, particularly horizontal wells for low permeability and thin reservoirs; EOR techniques, such as thermal recovery for heavy oil, and carbon dioxide $\left(\mathrm{CO}_{2}\right)$, hydrocarbon or chemical injection for lighter oil; improved logging and coring tools; and more sophisticated reservoir simulation models. Figure 2 shows U.S. EOR average daily production from January 1, 1984 (for 1983) through January 1, 2000 (for 1999). In 1999 (reported 


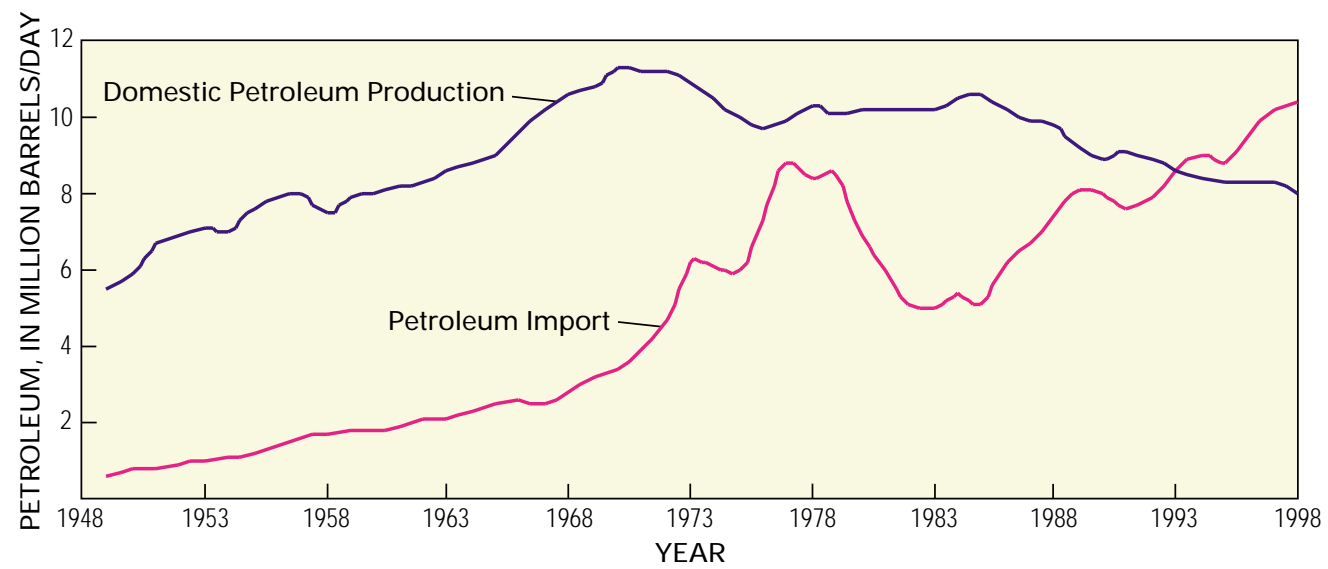

Figure 1. U.S. petroleum production and imports, in million barrels per day from 1948 through 1998. Domestic petroleum production includes crude oil, lease condensate and natural gas plant liquids; petroleum imports include crude oil and petroleum products. Data from Annual Energy Review 1998, Energy Information Administration, 1999, p. 119.

as of January 1, 2000), EOR processes contributed 748,000 barrels per day to U.S. oil production or, about 12 percent of U.S. oil production, a percentage that is consistent with 1997 levels (reported as of January 1, 1998) (Moritis, 2000).

Thermal recovery, $\mathrm{CO}_{2}$ gas injection and miscible/immiscible hydrocarbon gas injection are the EOR techniques that have contributed the most to field growth. At the year-end 1999, 86 thermal recovery, $64 \mathrm{CO}_{2}$ injection, and 6 hydrocarbon miscible/immiscible gas injection projects were in operation in the U.S. (Moritis, 2000). It is important to note that despite the decline in number of EOR projects in the U.S. and the low price of oil during 1998-1999, the EOR production was still a significant portion of the U.S. total oil production (about 12 percent). Among the various thermal recovery techniques, steam flooding is the most widely used method. Of the various gas injection processes, miscible $\mathrm{CO}_{2}$ injection process has been a preferred option because it is usually more efficient in displacing oil than any other gas injection process. Miscible/immiscible hydrocarbon gas injection is technically complex and relatively more expensive. In the miscible gas injection process, the injection gas and the reservoir oil form a single phase, resulting in significantly higher oil recoveries. In the immiscible gas injection process, the injection gas and reservoir oil remain as two separate phases and the oil recoveries are not as high as in the miscible gas injection process.

Thermal recovery and $\mathrm{CO}_{2}$ injection processes are technically and economically the most successful EOR techniques and will continue to play an important role in the field growth phenomenon. The key to expanding the use of the technically proven EOR processes is the reduction of implementation costs. One recent example is an innovative thermal recovery (steam-cogeneration) project in the Wilmington field, California where steam was used first to produce electricity generating extra revenue and then was injected into reservoirs to mobilize viscous oil for better recovery (Moritis, 1998).

\section{Field Grow th in Major Petroleum Production Regions}

Field growth is seen in most of the petroleum provinces of the world. The results of detailed study by the USGS in two regions, the onshore United States and Russia, are briefly described.

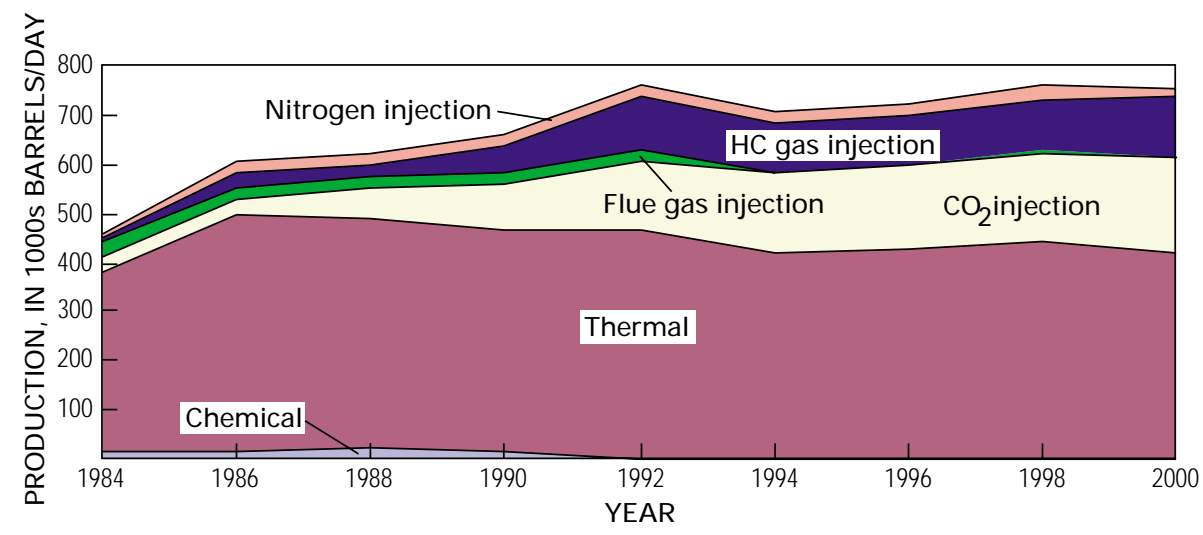

Figure 2. U.S. enhanced oil recovery (EOR) production using following methods: chemical, thermal, CO2 injection, flue gas injection, miscible/immiscible hydrocarbon gas injection and nitrogen injection processes. Data from M oritis, 2000, p. 39-61. 


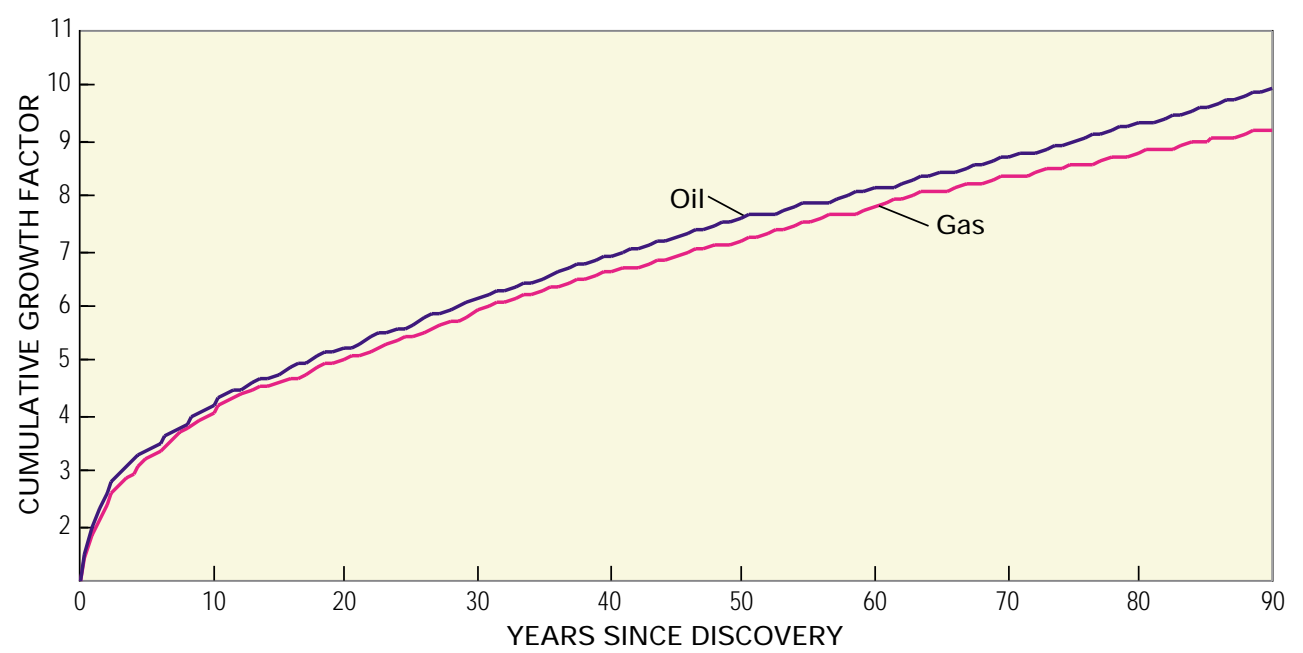

Figure 3. U.S. cumulative reserve grow th of oil and gas fields. Data from 1995 USGS National Oil and Gas Resource Assessment reported by Attanasi, and others, 1999, p. 79-81.

\section{United States}

The onshore fields of the conterminous United States were studied as part of the 1995 USGS National Oil and Gas Resource Assessment (reported by Attanasi and others, 1999) and are summarized in figure 3 .

After 90 years of production, reserves continue to grow for both oil and gas. As part of their study, Attanasi and Root (1994) divided U.S. onshore fields into two groups, common and outlier fields. Outlier fields were defined as fields whose reserve growth deviated from the general trend of common fields. Fields with heavy oil, such as the Midway-Sunset field in California, where a sudden increase in recovery many years after discovery is attributed to the application of thermal recovery methods, are considered to be outliers. Fields with low permeability or continuous gas reservoirs, where development seems to be especially sensitive to gas price fluctuations, are also considered to be outlier. Because the expected growth rate for common and outlier fields are different, they were evaluated separately. Although outlier fields were defined differently by Attanasi and Root (1994) and in the 1995 National Oil and Gas Resource Assessment (Attanasi and others, 1999), the overall reserve growth trends are similar. Cumulative growth factors (multiples of reserve value at discovery) 90 years after discovery from the two studies were slightly different with results from Attanasi and Root (1994) and Attanasi and others (1999) shown as follows: cumulative growth factors of 10.8 and 10.0 for oil fields and 8.6 and 9.2 for gas fields, respectively.

Although the reserve growth in common fields, as shown above, is attributed primarily to water flood as well as to other EOR techniqes, it is not large enough to offset the decline in the remaining proved oil reserves caused by the ongoing production from the existing fields. The U.S remaining proved oil reserves grew from 22.02 billion barrels on January 1,1998 to 22.55 billion barrels on January 1, 1999 (Oil \& Gas Journal, 1998), but the high oil production rate of 6.4 million barrels/day (or annual production of 2.3 billion barrels) in 1998 would deplete the remaining reserves fast without continued field growth. The application of EOR techniques has occurred in only a limited number of fields to date. Therefore, there is potential for additional reserves if EOR techniques are extended to other fields. Further studies are required to improve the economics of technically proven EOR techniques for their application to other fields including remote and even relatively smaller fields.

\section{Russia}

As part of the assessment of reserve growth, Verma and others (2000) evaluated field growth in the Volga-Ural province of Russia. In their ongoing study, they also noted similar reserve growth in the West Siberian province of Russia. The Volga-Ural province has shown cumulative reserve (field) growth factors of 3-5 during the first 30 years since discovery of the oil fields. Because of the time required in Russia to develop a field, defining field growth is more complex than in the U.S. For the study on the Volga-Ural province, the field's effective discovery years is redefined as either the year of first significant reserve reporting or the year of first production.

Volga-Ural and West Siberia provinces show most of their reserve growth in the first 5-7 years after discovery and little or no growth thereafter. It is difficult to compare the growth in Russian fields with those of the U.S. fields where growth continues even after 90 years, because in Russia oil fields are first evaluated over a 5-7 year period before being produced whereas in the U.S. both the evaluation and production of fields start shortly after their discovery. To further complicate the comparison, proved reserves in Russia generally include only primary and secondary (water flood) recoveries, although in the U.S. the reserves are revised regularly and include water flood and EOR recoveries. Other factors such as the Russian oil industry's lack of infrastructure, operational and economic problems in maintaining and developing fields, reporting requirements and documentation, and changes in the political system may have contributed to the difference in reserve growth. 


\section{Conclusions}

- Field growth occurs in almost all petroleum provinces of the world primarily due to the advancement of technology in various aspects of petroleum exploration and development.

- Field growth is considered to be the most important source for additional reserves in the U.S. In order to maintain or raise the current level of field growth, research on various aspects of proven EOR methods, particularly the economics, would be of value. While talking about improving economics of EOR techniques, it is important to point out that if stripper wells (producing 10-15 barrels per day or less) and associated production facilities that are in reasonable mechanical condition, continue to be operated or suspended rather than shut-in for long periods of time or abandoned, the economic viability of EOR application in smaller fields or parts of larger fields will definitely improve.

- Opportunities exist to increase U.S. oil reserves, through the application of proven EOR processes.

\section{References}

Arrington, J.R., 1960, Size of crude reserves is key to evaluating exploration programs: Oil \& Gas Journal, v. 58, no. 9, p. 130-134.

Attanasi, E.D., and Root, D.H., 1994, The enigma of oil and gas field growth: American Association of Petroleum Geologists Bulletin, v. 78, no. 33, p. 321-332.

Attanasi, E.D., Mast, R.F., and Root, D.H., 1999, Oil, gas field growth projections-Wishful thinking or reality: Oil \& Gas Journal, v. 97, no. 14, p. 79-81.
Energy Information Administration, 1990, The domestic oil and gas recoverable resource base-Supporting analysis for the national energy strategy: U.S. Department of Energy, Energy Information Administration SR/NES/90-05, 56 p.

Energy Information Administration, 1999, Annual Energy Review 1998: U.S. Department of Energy, Energy Information Administration DOE/EIA-0384 (98), July, p. 119.

Moritis, Guntis, 1998, EOR production up slightly: Oil \& Gas Journal, v. 96, no. 16, p. 49-56.

Moritis, Guntis, 2000, EOR weathers low oil prices: Oil \& Gas Journal, v. 98, no. 12, p. 39-61.

Oil \& Gas Journal, 1998, Worldwide look at reserves and production: Oil \& Gas Journal, v. 96, no. 52, p. 38-68.

Schmoker, J.W. and Attanasi, E.D., 1996, The importance of reserve growth to the nation's supply of natural gas: U.S. Geological Survey Fact Sheet FS-202-96, 2 p.

Verma, M.K., Ulmishek, G.F., Gilbershtein, A.P., 2000, Oil and Gas reserve growth-A model for the Volga-Ural Province, Russia: Proceedings of SPE/AAPG Western Regional Meeting, June 19-23, Long Beach, California, SPE no. 62616, $10 \mathrm{p}$.

\section{For more information, contact:}

Mahendra K. Verma

Denver Federal Center, Box 25046, MS 939

Denver, CO 80225

Phone 303-236-1746

E-mail mverma@usgs.gov 